\title{
Support the frontliners - good initiatives during the COVID-19 pandemic for healthcare workers across the world: is this what we really need?
}

\author{
Ruta Karaliuniene, ${ }^{1}$ (1) Sachin Nagendrappa, ${ }^{2}$ (1) Chonnakarn Jatchavala, ${ }^{3}$ (1) \\ Margaret Isioma Ojeahere, ${ }^{4}$ (1) Irfan Ullah, ${ }^{5}$ (i) Drita Gashi Bytyçi, ${ }^{6}$ (1) \\ Oluseun Peter Ogunnubi, (1) Michele Cherro, ${ }^{8}$ \\ Mohammadreza Shalbafan, ${ }^{9}$ (1) Camille Noël, ${ }^{10}$ Jairo M. Gonzalez-Diaz, ${ }^{11}$ (1) \\ Ramya Vadivel, ${ }^{12}$ (1) Victor Pereira-Sanchez, ${ }^{13}$ (1) Mohammad Abu Slaih, ${ }^{14}$ (1) \\ Sheikh Shoib ${ }^{15}$ (1) and Renato de Filippis ${ }^{16}$ (i)
}

1Elblandklinikum Radebeul, Technical University Dresden, Germany ${ }^{2}$ Assistant Professor, St John's Medical College Hospital, Bengaluru, India

${ }^{3}$ Assistant Professor of Psychiatry, Department of Psychiatry,

Faculty of Medicine, Prince of

Songkla University, Thailand

${ }^{4}$ Department of Psychiatry, Jos University Teaching Hospital, Jos, Plateau State, Nigeria

${ }^{5}$ Institute of Public Health \& Social Sciences (IPH\&SS), Khyber Medical University, Peshawar,

Pakistan

${ }^{6}$ Hospital and University Clinical Service of Kosovo, Mental Health Center Prizren, Kosovo

${ }^{7}$ College of Medicine, University of Lagos, Nigeria

${ }^{8}$ American University of Beirut Medical Center, Lebanon

${ }^{9}$ Assistant Professor of Psychiatry, Mental Health Research Center, Psychosocial Health Research Institute (PHRI), Department of Psychiatry, Schoo of Medicine Iran University of ces, Tehran, Iran

${ }^{10}$ Scientific collaborator, Child Psychiatry Department, Saint Peter University Hospital, Université Libre de Bruxelles, Brussels, Belgium

${ }^{11}$ CERSAME - UR Center for Mental Health, School of Medicine and Health Sciences, Universidad del Rosario, Bogotá, Colombia

${ }^{12}$ Walkato District Health Board Hamilton, New Zealand

${ }^{13}$ Clinical Assistant Professor, Department of Child

and Adolescent Psychiatry, NYU Grossman School of Medicine, New York, New York, USA

${ }^{14}$ National Center for Mental Health, Jordanian Ministry of Health, Amman, Jordan

${ }^{15}$ Department of Psychiatry, Jawahar Lal Nehru Memorial Hospital (JLNMH), Rainawari, Srinagar, Jammu and Kashmir, India

${ }^{16} \mathrm{PhD}$ student, Psychiatry Unit, Department of Health Sciences,
Healthcare workers have faced an unprecedented workload in overstretched health facilities during the COVID-19 pandemic, and we describe various initiatives to support them. Psychological, financial and peer support, accommodation and meal services, proper personal protective equipment, applause and gratitude in the community, spiritual and religious life, child care and volunteering were identified. The potential effects of the COVID-19 pandemic permanent stress, burnout and other mental health problems among healthcare professionals - can be expected to grow. Continued monitoring is essential to bolster resilience among healthcare workers and prevent the possible consequences for their mental health.

International scientific literature since the early stages of the COVID-19 pandemic has documented how healthcare workers, particularly those deployed at the 'front line', are being exposed to high risk of psychological distress and psychiatric symptoms such as depression, anxiety and insomnia. ${ }^{1}$ An unprecedented workload in overstretched health facilities and all the uncertainties of the pandemic make their working environment stressful and frightening. Factors associated with negative mental health outcomes in this population include long shifts, shortage of personal protective equipment (PPE), the risk of getting infected and transmitting the disease to their relatives, fatigue, the need for separation from their families and feelings of loneliness. Another described problem is the stigma against them as potential carriers of the infection. ${ }^{2}$

Burnout has been described as a psychological distress syndrome resulting from excessive and chronic workplace interpersonal stress not successfully managed. This condition shows up with a state of emotional, physical and mental exhaustion characterised by three key symptoms: overwhelming exhaustion, feelings of cynicism and detachment from the job, and a sense of ineffectiveness and lack of accomplishment. ${ }^{3}$ Prior to this pandemic, studies had already shown increased rates of burnout among healthcare workers in comparison with the general population, with a prevalence varying between 25 and $60 \%$. ${ }^{4}$ As burnout is well-known to have an effect not only on the individual, but also on their environment, thereby increasing the risk of healthcare errors, it is crucial to prevent it or address it early. A recent Austrian analysis of resilience in a healthcare system exposed to COVID-19 revealed that, although most healthcare systems are structured for delivering continuous medical services in normal circumstances, they may not be resilient enough to handle public health crises and other disasters. ${ }^{5}$

In this article, we collected contributions from colleagues across world regions, who are members of a research think tank assembled through the World Psychiatric Association (WPA) Section of Early Career Psychiatrists (ECP Section). ${ }^{6}$ Our objective is to describe an array of initiatives to support healthcare workers during the COVID-19 pandemic in different countries in the world.

\section{Method}

International data and information were collected by members of the ECP Section of the WPA, using an existing validated methodology. ${ }^{7,8}$ The ECP Section is a formal division of the WPA which represents and supports psychiatric trainees and ECPs (up to 7 years after completion of their training in psychiatry, regardless of age). ${ }^{6}$ Group discussions and conferences were held via online messaging and meeting platforms such as emails, WhatsApp and Zoom.

In the present study, 16 ECPs ( 5 females and 11 males) from 15 countries (at least 1 from each of the 5 continents of Africa, Asia, Europe, America and Australia) were approached between 
University Magna Graecia of Catanzaro, Italy.

Email: defilippisrenato@gmail. com

Keywords. COVID-19; front-line healthcare; healthcare workers: resilience; support.

First received 14 Sep 2021 Final revision 26 Dec 2021 Accepted 22 Jan 2022

doi:10.1192/bji.2022.6

(c) The Author(s), 2022. Published by Cambridge University Press on behalf of the Royal College of Psychiatrists. This is an Open Access article, distributed under Access article, distributed
the terms of the Creative Commons Attribution licence (https://creativecommons.org/ licenses/by/4.0/), which permits unrestricted re-use, distribution, and reproduction in any and reproduction in any medium, provided the original work is properly cited.
June and August 2020 by the lead (R.K.), co-lead (S.N.) and senior lead (R.d.F.) authors via WhatsApp and emails to share data and information about the good initiatives to support healthcare workers during the COVID-19 pandemic in their own country.

\section{Results}

We identified ten groups of initiatives implemented across countries (Table 1). In general terms, some countries have continued to build on the lessons learned and existing structures from the Ebola virus disease outbreak and in combating poliomyelitis, ${ }^{9}$ whereas the current pandemic was a new challenge for the others.

\section{Psychological support}

Most contributors in our group reported that many hospitals and governmental institutions have activated psychological support guidelines and tools to counteract symptoms of burnout and adaptation (adjustment) disorders associated with the new situation in their countries. Also, services providing psychological help specifically for healthcare workers were expanded, being offered not only in major cities, but also in rural areas. Virtual group therapy and individual face-to-face as well as tele-psychiatry interventions have also been offered. Training groups for 'life skills' such as stress and anger management have been established. This is an important step, as psychoeducation via digital learning addressing mental health concerns has been found to be effective. ${ }^{10}$

\section{Accommodation services}

In most of the countries represented in our group numerous tour operators, hotels and homeowners has made their facilities available free of charge or affordable for healthcare workers and their families. In some cases, private healthcare centres housed their staff in hotels that had been closed during the lockdown, intending to keep workers' families safe from contagion. ${ }^{11}$ However, only a few institutions could sustain this approach on account of the increasing costs and the indefinite nature of the pandemic. Some privately owned institutions currently run fortnight shifts where healthcare workers are lodged in nearby hotels for 2 weeks.

\section{Meal services}

Many restaurants in Italy have offered free meals delivered directly to hospitals, ensuring catering for healthcare workers. Additionally, local restaurants in countries such as Lebanon and Colombia have waived bills for healthcare workers in hospital areas or have donated their products to doctors and nurses as a token of appreciation, as it has been suggested that nutrition, rest breaks, time to decompress and time off are just important as providing PPE. ${ }^{12}$

\section{Proper personal protective equipment}

Most contributors reported that voluntary and non-profit associations purchased proper PPE and other basic medical equipment for emergency rooms and intensive care units in the most serious phase of the shortages. As increasing fear of contracting coronavirus among healthcare workers was reported, this initiative seems to be important not only by ensuring their safety, but also by contributing to preventing psychological distress. $^{13}$

\section{Gratitude in communities}

On a larger scale, communities in different countries came together with group rounds of applause in support of all the front-line healthcare workers. The ongoing pandemic revealed the unmet needs of healthcare workers. Feeling valued by receiving the gratitude of communities, especially positive attitudes such as recognition and awareness in the media, could add to individuals' coping strategies, strengthening their mental resilience. ${ }^{14}$

\section{Financial support}

Contributors in our group also reported that economic bonuses were offered to healthcare workers for babysitting services and summer camps for children, and free taxi services for the commute to hospitals were granted. In addition, in some countries (e.g. Belgium, Italy, the USA) banks also decided to delay or defer the payment of mortgage and loan instalments. In Nigeria, an increase in hazard allowances was paid to healthcare workers. ${ }^{4}$ In India, COVID-19 allowances were paid to healthcare workers in addition to the existing salary for their relentless service during the pandemic.

\section{Spiritual and religious life}

As the toll of the pandemic continues to increase and thousands of unexpected deaths add up, many healthcare workers are exposed to grief that could have a lasting impact, leading to emotional distress and possibly to mental disorders. In some countries, community leaders have been facilitating COVID-safe engagement in religious and spiritual practices. For healthcare workers who consider themselves spiritual, but not religious, non-denominational spiritual support has been reported as being helpful. For example, some doctors in Nigeria have a daily 'time out' and pray with their families and friends where they maintain contact and receive support via interactive apps. Most contributors reported that religious practices are helping healthcare workers to cope better and stay resilient, which supports previous observations of religion and spirituality as being important in mental health. ${ }^{15}$

\section{Child care}

School closures in affected countries created unintended child care obligations for healthcare 
Table 1

Overview of initiatives to support front-line healthcare workers during the COVID-19 pandemic across the world

\begin{tabular}{|c|c|c|}
\hline Initiative & Examples & Possible benefits \\
\hline Psychological support & $\begin{array}{l}\text { Guidelines and tools to counteract burnout and adaptation (adjustment) } \\
\text { disorders } \\
\text { Online groups } \\
\text { Psychological hotlines }\end{array}$ & $\begin{array}{l}\text { Early detection and prevention of mental disorders } \\
\text { among healthcare workers }\end{array}$ \\
\hline Accommodation services & $\begin{array}{l}\text { Numerous tour operators, hoteliers or simple homeowners have made their } \\
\text { facilities available free of charge or at affordable rates }\end{array}$ & $\begin{array}{l}\text { Helping healthcare workers to maintain the safety of } \\
\text { their families }\end{array}$ \\
\hline Catering services & $\begin{array}{l}\text { Many restaurants have offered free meals } \\
\text { Meals delivery directly to hospitals }\end{array}$ & $\begin{array}{l}\text { Facilitating healthcare workers' nutrition during long } \\
\text { shifts }\end{array}$ \\
\hline $\begin{array}{l}\text { Proper personal protective } \\
\text { equipment }\end{array}$ & $\begin{array}{l}\text { Voluntary and non-profit associations have purchased PPE and medical } \\
\text { instruments for emergency rooms and intensive care units during the most serious } \\
\text { shortages }\end{array}$ & Relieving the fear of infection, ensuring security \\
\hline $\begin{array}{l}\text { Applause and gratitude in } \\
\text { the community }\end{array}$ & $\begin{array}{l}\text { In many parks and cities, murals and street art have been created to celebrate the } \\
\text { courage of healthcare professionals and the heroism of those who died working } \\
\text { on the front line } \\
\text { Applause on balconies }\end{array}$ & $\begin{array}{l}\text { Feeling the gratitude of others is associated with lower } \\
\text { levels of depression }\end{array}$ \\
\hline Spiritual and religious life & $\begin{array}{l}\text { Rituals and practices via interactive apps } \\
\text { Individual opportunities for religious activities } \\
\text { Individual time for spiritual needs }\end{array}$ & $\begin{array}{l}\text { Religion and spirituality have been reported to be } \\
\text { helpful in staying resilient }\end{array}$ \\
\hline Child care & Babysitting and child day care for healthcare workers & $\begin{array}{l}\text { Ensuring the care of children, solving the problem of } \\
\text { early and unexpected closure of kindergartens and } \\
\text { schools }\end{array}$ \\
\hline Voluntary help & $\begin{array}{l}\text { Volunteers at hospitals } \\
\text { Voluntary help in rural areas }\end{array}$ & Helped to avoid overload for front-line workers \\
\hline Peer support & $\begin{array}{l}\text { Online communication groups } \\
\text { Life skills training groups (stress, anger management) }\end{array}$ & $\begin{array}{l}\text { Elicit resilience through emotional and scientific } \\
\text { sharing }\end{array}$ \\
\hline
\end{tabular}

workers. ${ }^{16}$ The contributors agreed that the relocation of children to relatives with lesser risk of being infected was one of the most common solutions. Some faith-based and private organisations established crèches and offered free babysitting services for healthcare workers, with the appropriate safety measures. Nevertheless, a considerable proportion of healthcare workers needed their spouses take on additional responsibilities in assisting with child care, home schooling and other family demands. Likewise, older siblings among their children have had to take on more responsibilities.

\section{Voluntary help}

The increasing numbers of COVID-19 patients rapidly overloaded the healthcare systems in many countries, especially affecting working hours and shifts for healthcare workers. As many hospitals struggled with the shortage of employees, healthcare volunteers have played a key role in supporting healthcare workers, especially in early detection of COVID-19 within their communities. ${ }^{17}$ In many countries (e.g. India, Lebanon, Lithuania, Thailand), the number of volunteers on ambulances as well as in hospitals increased during the pandemic.

\section{Peer support}

In Thailand, access to online help groups tailored for healthcare workers was controlled (by providing medical council registration number, specialty and institution affiliation), to ensure that individuals felt secure and free to speak within the group. Publications in these groups' communication feeds were moderated by administrators to ensure mutual respect and avoid bigotry. Such groups seem to elicit resilience through emotional and scientific sharing. ${ }^{18}$ Most of the contributors in our team reported that anxiety has been palpable among healthcare workers in online groups. Nevertheless, the concerns expressed by participants in these groups are finding reassuring responses from experts of various backgrounds, information resources and available local healthcare networks. Peer support has also helped some workers cope with distress associated with the current workload and with being away from home. ${ }^{14}$

\section{Future directions}

It is still unclear whether the initiatives introduced to mitigate the effects of the COVID-19 pandemic could be helpful in the longer term and for the majority of healthcare workers. Further institutional support for these initiatives and cross-disciplinary research into their effectiveness and implementation are needed to properly address the needs of the healthcare workers at this challenging time for their profession.

Countries require effective systems to support healthcare workers and their families during 
unprecedented situations such as the COVID-19 pandemic, but the literature available on such support systems is scarce. There is an immediate need for research across the nations and the development of universal guidelines to help healthcare providers not only during this pandemic, but also in the future. In addition, there are instances where communities are not actively practising COVID-19 safety protocols such as maintaining social distancing, wearing masks and controlling public gathering, including antivaccine demonstrations. Policy makers still need to make efforts to provide adequate public education on following COVID-19 safety behaviours. This would help to reduce infections and thus reduce the burden on front-line workers.

\section{Discussion}

The COVID-19 pandemic has revealed preexisting inadequacies in the healthcare system. In the majority of the countries studied, especially the low- and middle-income countries, healthcare workers are underpaid, face increased workloads due to long-term staff shortages and lack facilities. This has an immense impact on the physical and mental health of healthcare providers and, with the COVID-19 pandemic, there is increased prevalence of anxiety, depression, stress and burnout across the world. Our identified initiatives (psychological, financial and peer support, accommodation and meal services, proper PPE, community gratitude, spirituality and religion, child care, voluntary help) have been reported to be helpful across different countries in the face of these problems.

\section{Data availability}

The data that support the findings of this study are available from the corresponding author on reasonable request.

\section{Acknowledgements}

We would like to acknowledge the Early Career Psychiatrists Section of the World Psychiatric Association, a supportive network that enabled us to liaise and collaborate on this publication. We thank all the front-line healthcare workers who worked, and still work, against COVID-19 all over the world.

\section{Author contributions}

R.K., S.N. and R.d.F. lead the group discussion and manuscript drafting, and reviewed the manuscript. All the authors agreed on the final draft before submission.

\section{Funding}

This research received no specific grant from any funding agency, commercial or not-for-profit sectors.

\section{Declaration of interest}

None.

\section{References}

1 Lai J, Ma S, Wang Y, Cai Z, Hu J, Wei N, et al. Factors associated with mental health outcomes among health care workers exposed to coronavirus disease 2019. JAMA Netw Open 2020 3(3): e203976.
2 Ransing R, Ramalho R, de Filippis R, Isioma Ojeahere M, Karaliuniene R, Orsolini L, et al. Infectious disease outbreak related stigma and discrimination during the COVID-19 pandemic: drivers, facilitators, manifestations, and outcomes across the world. Brain Behav Immun 2020; 89: 555-8.

3 Maslach C, Leiter MP. Understanding the burnout experience: recent research and its implications for psychiatry. World Psychiatry 2016; 15(2): 103-11.

4 Shanafelt T, Ripp J, Sinai M, Trockel M. Understanding and addressing sources of anxiety among health care professionals during the COVID-19 pandemic. JAMA, 2020; 23: 2133-4.

5 Jovanović A, Klimek P, Renn O, Schneider R, Øien K, Brown J, et al. Assessing resilience of healthcare infrastructure exposed to COVID-19: emerging risks, resilience indicators,

interdependencies and international standards. Environ Syst Decis [Epub ahead of print] 4 Jun 2020. Available from: https:// doi.org/10.1007/s10669-020-09779-8.

6 Pinto da Costa M. Early career psychiatrists - history, 2020 and beyond. World Psychiatry 2020; 19: 127-8.

7 Ojeahere MI, de Filippis R, Ransing R, Karaliuniene R, Ullah I, Bytyçi DG, et al. Management of psychiatric conditions and delirium during the COVID-19 pandemic across continents: the lessons thus far. Brain Behav Immun Health 2020; 9: 100147.

8 Schuh Teixeira AL, Spadini AV, Pereira-Sanchez V, Ojeahere MI, Morimoto K, Chang A, et al. The urge to implement and expand telepsychiatry during the COVID-19 crisis: early career psychiatrists' perspective. Rev Psiquiatr Salud Ment 2020; 13: 174-5.

9 World Health Organization. Nigeria's polio infrastructure bolster COVID-19 response. WHO, Regional Office for Africa, 2020 (https://www.afro.who.int/news/nigerias-polio-infrastructurebolster-covid-19-response).

10 Blake $\mathrm{H}$, Bermingham F, Johnson G, Tabner A. Mitigating the psychological impact of COVID-19 on healthcare workers: a digital learning package. Int J Environ Res Public Health 2020; 17(9): 2997.

11 Ohia C, Bakarey AS, Ahmad T. COVID-19 and Nigeria: putting the realities in context. Int J Infect Dis 2020; 95: 279-81.

12 Adams JG, Walls RM. Supporting the health care workforce during the COVID-19 global epidemic. JAMA 2020; 323: 1439-40.

13 Shacham M, Hamama-Raz Y, Kolerman R, Mijiritsky O, Ben-Ezra M, Mijiritsky E. COVID-19 factors and psychological factors associated with elevated psychological distress among dentists and dental hygienists in Israel. Int J Environ Res Public Health 2020; 17(8): 2900.

14 Billings J, Abou Seif N, Hegarty S, Ondruskova T, Soulios E, Bloomfield M, et al. What support do frontline workers want? A qualitative study of health and social care workers' experiences and views of psychosocial support during the COVID-19 pandemic. PLoS One 2021; 16(9): e0256454.

15 Milner K, Crawford P, Edgley A, Hare-Duke L, Slade M. The experiences of spirituality among adults with mental health difficulties: a qualitative systematic review. Epidemiol Psychiatr Sci 2019; 29: e34.

16 Bayham J, Fenichel EP. Impact of school closures for COVID-19 on the US health-care workforce and net mortality: a modelling study. Lancet Public Health 2020; 5(5): e271-8.

17 Thai Health Foundation. Thailand's One Million Health Volunteers Hailed as Coronavirus Heroes: Thai Health Promotion Foundation - The Sustainability of Well-Being for Thai People. Thai Health Foundation, 2020 (https://en.thaihealth.or.th/ Infographics/297/Thailand\%E2\%80\%99s\%20one\%20million\% 20health\%20volunteers\%20hailed\%20as\%20coronavirus\% 20heroes).

18 Moazzami B, Razavi-Khorasani N, Doghaei Moghadam A, Farrokhi E, Rezaei NC. COVID-19 and telemedicine: immediate action required for maintaining healthcare providers well-being. J Clin Virol 2020; 126: 104345. 